\title{
Leaders
}

\section{Update on central nervous system cytopathology. I. Cerebrospinal fluid}

\begin{abstract}
J E Bell
Introduction

Examination of cerebrospinal fluid provides extremely useful diagnostic information in many diseases of the central nervous system. In particular, analysis of cytological appearances may help to confirm or refute the presence of inflammatory or neoplastic processes in the subarachnoid compartment. This article explores some of the issues, both practical and theoretical, which influence the efficacy of this investigation and highlights the dilemmas and methodological pitfalls which may interfere with diagnostic accuracy.
\end{abstract}

\section{Normal physiology of cerebrospinal fluid} Cerebrospinal fluid (CSF) is produced within the ventricular system of the brain by secretion from choroid plexuses at a rate of about $500 \mathrm{ml}$ a day. ${ }^{1}$ The CSF circulates through the ventricular system, escaping through the foramina of the roof of the fourth ventricle into the subarachnoid space, before being reabsorbed under normal circumstances through the arachnoid granulations into the venous sinuses of the dura mater. ${ }^{1}$ The spinal and cranial subarachnoid spaces are in continuity unless there is obstruction at the foramen magnum. The central canal of the spinal cord, although patent during development and in early life, is frequently occluded in later life and may not contain CSF.

CSF is normally crystal clear and colourless, and should contain no more than $5 \times 10^{6}$ cells per litre in samples aspirated from the lumbar cistern. ${ }^{1}$ These cells are predominantly lymphocytes. Normal CSF contains glucose at a level approximately two thirds of that in blood but the protein content is very low. The table lists normal CSF values together with abnormal findings which are indicative of various pathological conditions. In adult life the protein content of lumbar CSF is somewhat higher than that of ventric-

CSF findings in central nervous system infections and inflammations

\begin{tabular}{|c|c|c|c|}
\hline Infection & Protein & Glucose & Cells \\
\hline $\begin{array}{l}\text { Normal } \\
\text { Bacterial } \\
\text { Tuberculous }\end{array}$ & $\begin{array}{l}0 \cdot 1-0 \cdot 45 \mathrm{~g} / 1 \\
\text { Raised: } 0 \cdot 5-5 \mathrm{~g} / 1 \\
\text { Raised: } 0 \cdot 5-2 \mathrm{~g} / 1\end{array}$ & $\begin{array}{l}2.5-4 \mathrm{mmol} / 1 \\
\text { Reduced: } 0-2.0 \mathrm{mmol} / 1 \\
\text { Reduced: } \\
1.2-2.0 \mathrm{mmol} / 1\end{array}$ & $\begin{array}{l}<5 \times 10^{6} / 1 \text { lymphocytes } \\
\text { Many polymorphs } \\
\text { Polymorphs early, } \\
\text { lymphocytes later }\end{array}$ \\
\hline Viral & $\begin{array}{l}\text { Slightly raised } \\
0.5-1.5 \mathrm{~g} / 1\end{array}$ & Normal & Polymorphs early, \\
\hline Multiple sclerosis & $\begin{array}{l}\text { Oligoclonal IgG } \\
\text { on electrophoresis }\end{array}$ & Normal & Lymphocytes \\
\hline
\end{tabular}

ular CSF. ${ }^{1}$ Fetal CSF is comparatively rich in protein. $^{2}$

\section{Indications for cytological examination of CSF}

CSF is usually submitted for cytological examination to confirm, or help to exclude, a diagnosis of infective, inflammatory, or neoplastic processes in the subarachnoid compartment. Samples are sometimes submitted to the laboratory following other procedures such as a myelogram, administration of intrathecal drugs, or in dementia of early onset. In these circumstances negative CSF cytology can be reassuring. Certain features, such as a higher than normal opening intrathecal pressure, or raised protein concentrations, or cell counts, are frequently predictive of abnormal CSF cytology. ${ }^{3}$

Samples of CSF are usually obtained from the lumbar subarachnoid space and only rarely nowadays from the cisterna magna. Ventricular samples can be obtained during operation, during positioning of a CSF access device, or during or after placement of a ven-

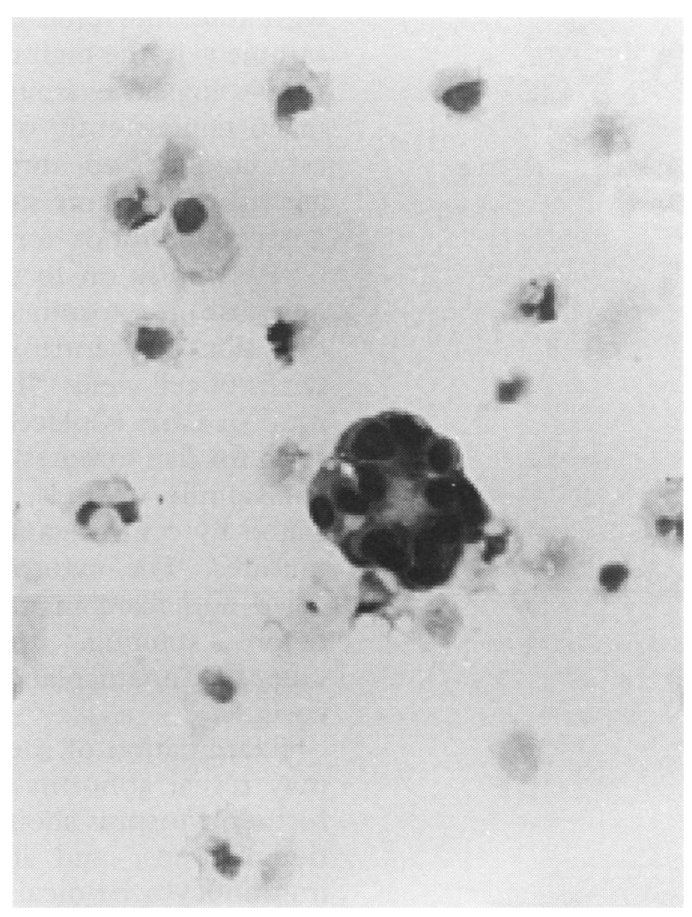

Figure 1 Ventricular sample of CSF contains macrophage-like cells and a cytologically benign clump of cells probably derived from choroid plexus (Giemsa). 
triculo-peritoneal shunt. Ventricular samples are noticeably more cellular than lumbar samples and may contain small fragments of brain or choroid plexus tissue ${ }^{4}$ (fig 1). Cisternal samples are more likely than lumbar samples to be positive in cases of neoplastic spread in CSF. ${ }^{5}$ It follows that knowledge of the source of the sample, as well as the clinical history, is important for interpretation of CSF findings. It should be noted that CSF samples obtained after death, even from the lumbar subarachnoid space, are hypercellular compared with samples obtained during life, due to shedding of cells. ${ }^{6}$ This also occurs in "respirator brain," where fragments of cerebellum can be found in lumbar CSF samples: this may cause diagnostic confusion. ${ }^{7}$ These shed cells should not be interpreted necessarily as evidence of inflammation or of other clinically relevant antemortem pathological processes.

It is appropriate to request repeat CSF samples in diagnostically difficult cases or when the sample has been unsatisfactory, or to chart progress of certain diseases including subarachnoid disease in leukaemia and primary brain neoplasms. ${ }^{8}$

\section{Preparation of samples}

It is important to ensure that CSF samples reach the laboratory as soon as possible after the lumbar puncture because cells in CSF deteriorate rapidly. ${ }^{9}$ The accompanying request form should contain sufficient clinical detail to ensure that the sample does not pose a high risk to the laboratory staff, and to assist in interpretation of the findings. Volume, colour, and clarity of the specimen should be noted at the time of receipt. A cell count should be performed using standard counting chambers into which a drop of CSF stained with toluidine blue is introduced unless the sample is in the high risk category.

Cytological examination should be undertaken concurrently with glucose and protein estimations, and antibody titres if appropriate, all in the same sample of CSF. Of all the possible methods for transferring cells from CSF samples on to slides, most laboratories now use a cytospin apparatus, ${ }^{4}$ such as the Shandon cytocentrifuge, which is efficient in terms of cell yield. ${ }^{10}$ To prepare cytospins, $0 \cdot 2$ $\mathrm{mm}^{3}$ of CSF is placed in balanced wells and spun for five minutes at $600 \mathrm{rpm}$. If the original sample exceeds $1 \mathrm{ml}$, it is pre-concentrated by centrifugation at $2000 \mathrm{rpm}$ for five minutes. The cytospin preparations are air dried and fixed in methanol for 10 minutes before staining. Routine stains include Giemsa, Papanicolaou, and haematoxylin and eosin.

Examination of routinely stained cytospins may reveal abnormalities which suggest that further cytospins should be prepared for additional stains, and if these are to include immunocytochemical procedures, the spare cytospins should be fixed in cold acetone for five minutes. Additional routine stains include Gram, Ziehl Neelsen, periodic acid
Schiff, Perls's and Masson Fontana. Immunocytochemical or immunofluorescence studies help to identify cellular subpopulations. ${ }^{9}$ Antibodies of interest include epithelial markers (cytokeratin, epithelial membrane antigen) lymphoid and macrophage markers (leucocyte common antigen, panel of $T$ and B cell markers, and PGM1) and neuroectodermal markers (glial fibrillary acidic protein, PGP $9 \cdot 5$, and S100 protein). S100 protein is also a marker for melanoma cells. An antibody to placental alkaline phosphatase may assist in the identification of germ cell tumours. Double immunofluorescence preparations can be considered when only limited numbers of cytospin preparations are available.

\section{Cytology findings in CSF samples HAEMORRHAGE}

In a so-called traumatic tap peripheral blood can be introduced into CSF during aspiration of the sample. In this case the sample will appear blood-stained but on settling the CSF supernatant fluid is clear. Genuine subarachnoid haemorrhage may be marked by xanthochromia of the supernatant fluid, and spectroscopy can be used to detect haemoglobin and bilirubin. In either case red blood cells, together with an appropriate number of mixed white cells, are present in the sample on cytological examination. Pigment-laden macrophages which prove positive with a Perls's Prussian Blue reaction provide evidence of previous haemorrhage (fig 2).

\section{ACUTE INFLAMMATORY INFILTRATE}

The infiltrate is characterised by the presence of polymorphs without an accompanying appropriate number of red blood cells.

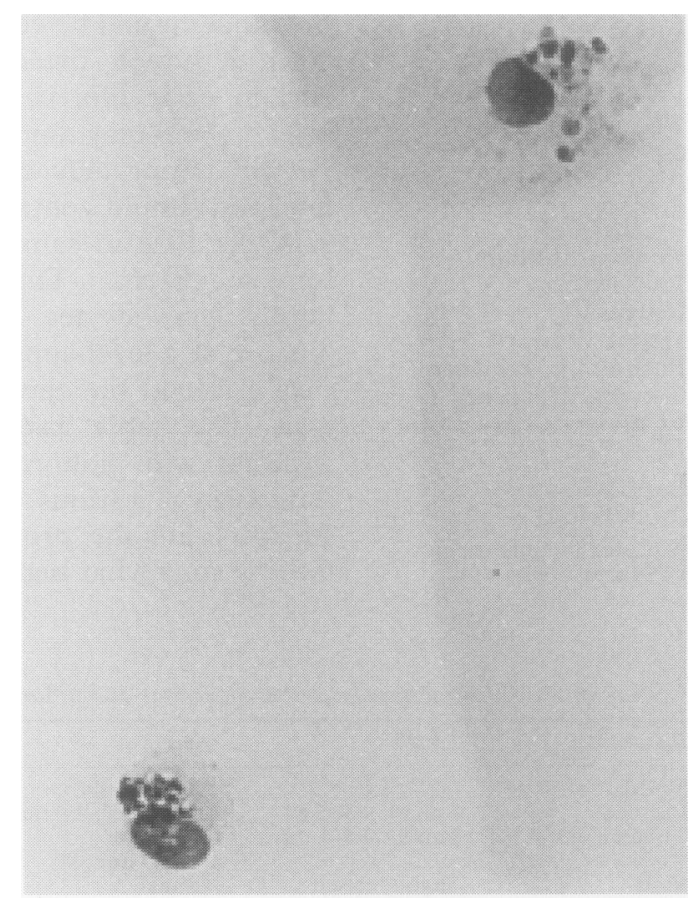

Figure 2 Two macrophages showing pigmented inclusions in the cytoplasm, from a patient with previous subarachnoid haemorrhage (haematoxylin and eosin). 
Although bacterial infection is the most usual cause, early viral, tuberculous, and fungal infections also provoke an initial polymorphonuclear leucocyte reaction. ${ }^{9}$ An acute inflammatory infiltrate in the subarachnoid space is occasionally due to necrotising processes in the brain or spinal cord such as surfacing infarcts or malignant tumours. Other conditions associated with polymorph infiltration include epilepsy and reactions to intrathecal drugs, while CSF eosinophilia may be a response to drugs, or shunt procedures, or to metastatic disease in the leptomeninges. ${ }^{9}$ Infecting organisms, particularly Gram positive bacteria, or fungi such as Cryptococcus sp, may sometimes be identified in the CSF by special stains. However, bacterial and viral agents are more likely to be characterised accurately by microbiological investigation, which also forms the basis for appropriate drug treatment.

\section{CHRONIC INFLAMMATORY INFILTRATE}

This is characterised by lymphocytes and usually macrophages (fig 3 ). In active chronic inflammation plasmacytoid cells may be present (fig 4). Typically, this type of infiltrate is seen in the active stages of viral and tuberculous infections, and should prompt microbiological investigation of the sample if the clinical history is appropriate and if this has not already been undertaken. However, infective causes are rarer in Western practice than non-infective inflammatory causes. Small but clinically important numbers of CSF lymphocytes are often seen in the active phases of multiple sclerosis, and occasionally result simply from irritation of the leptomeningesfor example, by a prolapsed disc. Reactive and infective lymphoid infiltrates are polyclonal and include mixed $B$ and $T$ cells,

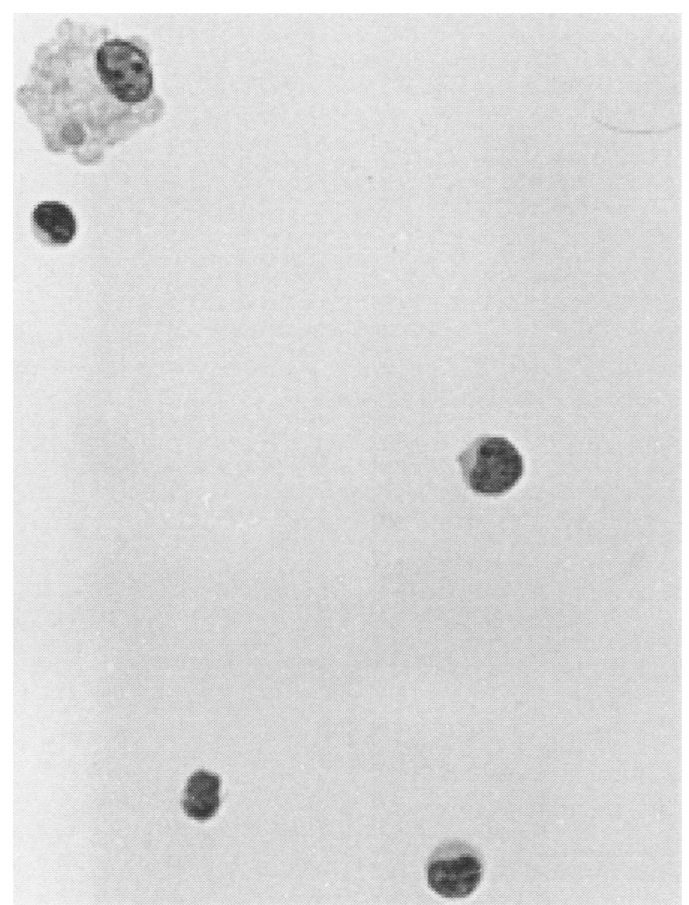

Figure 3 Chronic inflammatory infiltrate in CSF showing lymphocytes and a macrophage (top left) (haematoxylin and eosin). identified by immunocytochemical staining of spare cytospin preparations. ${ }^{9}$

A summary of the CSF findings in infective and inflammatory conditions is shown in the table.

\section{NEOPLASTIC INFILTRATION}

Malignant cells can be shed into the CSF from primary tumours of the central nervous system (CNS), particularly medulloblastomas, ependymomas, pineal tumours, primary CNS lymphomas and less commonly from gliomas (fig 5). Although primary tumours rarely metastasise outwith the CNS, they have a capacity for seeding through the subarachnoid space. ${ }^{11}$ Subarachnoid spread may also complicate recurrence of a previously treated intrinsic CNS tumour.

Malignant cells can also be present in the CSF as a result of metastatic spread from tumours arising in other systems, including carcinoma (fig 6), melanoma, non-CNS lymphoma and sarcoma. ${ }^{4}$ Tumours of the breast, lung, and prostate tend to spread in the subarachnoid compartment and melanomas also frequently metastasise here. ${ }^{9}$ Cranial and spinal nerves may be invaded by collections of metastatic tumour cells, particularly by lymphoma. Occasionally the primary tumour is occult and meningeal disease is the first clinical indication of disease. Analysis of CSF cytology, particularly by immunocytochemical investigation, may suggest possible primary sites. Routine follow up of cases of leukaemia may reveal blast cells in the CSF, the presence of which would prompt appropriate CNS directed treatment.

Highly atypical or frankly malignant cells can be present in cytospin preparations of CSF either singly (fig 6) or in clumps (fig 7), and their nature and origin is further defin-

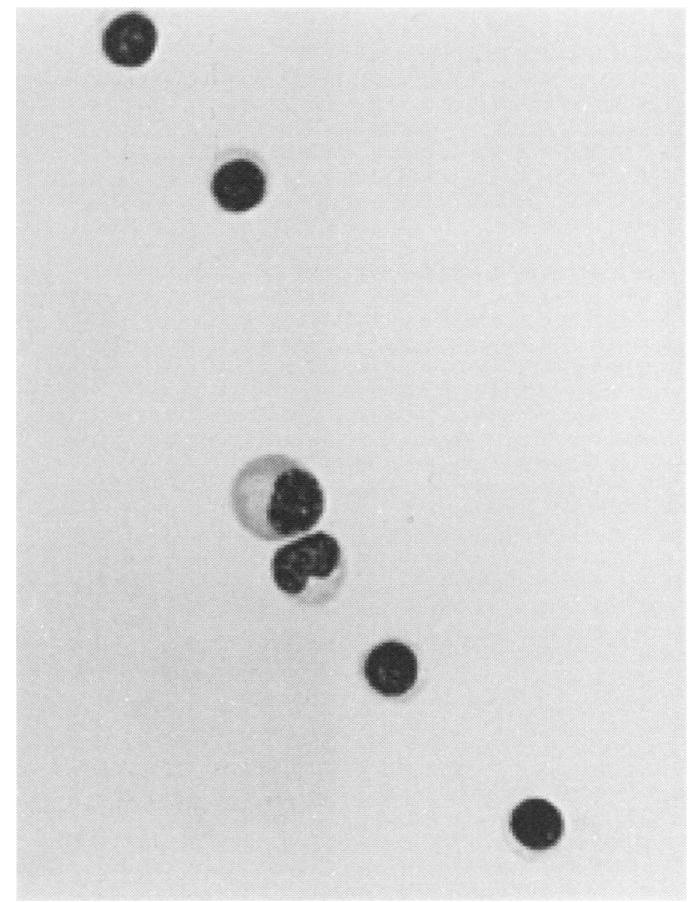

Figure 4 Chronic inflammatory infiltrate in CSF showing plasmacytoid cells (centre) in addition to lymphocytes (haematoxylin and eosin). 


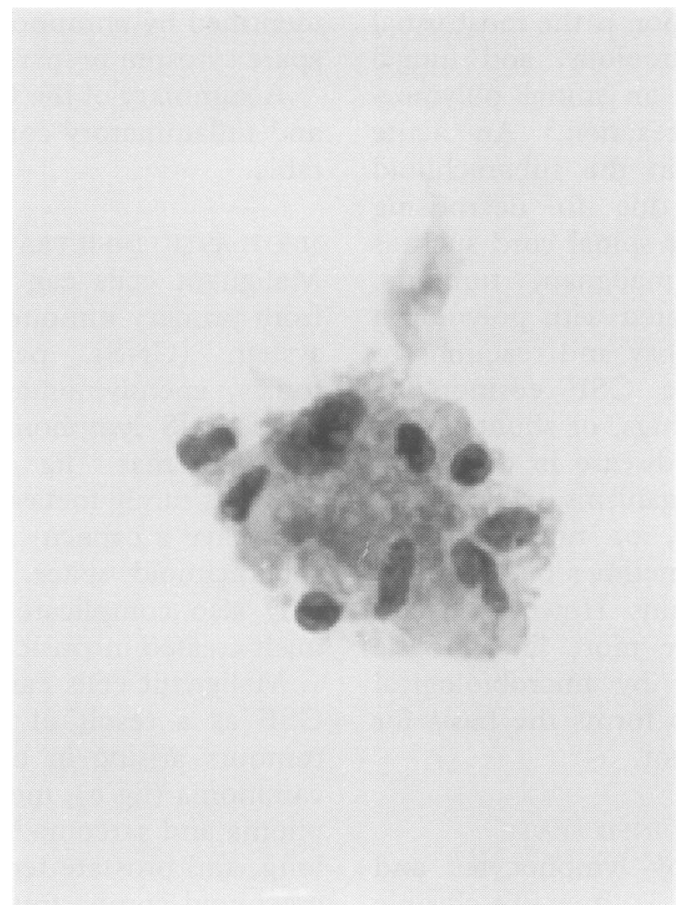

Figure 5 Clump of glioma cells in specimen of lumbar $C S F$ aspirated 10 days after biopsy of the primary tumour (haematoxylin and eosin).

able by immunocytochemical techniques (figs 8 and 9). If there is insufficient CSF in the original sample for more detailed studies a repeat sample should be requested. Malignant CSF cellular infiltrates are very frequently accompanied by a raised CSF protein concentration.

\section{Dilemmas and pitfalls in CSF} examination

The diagnostic dilemmas are of two main

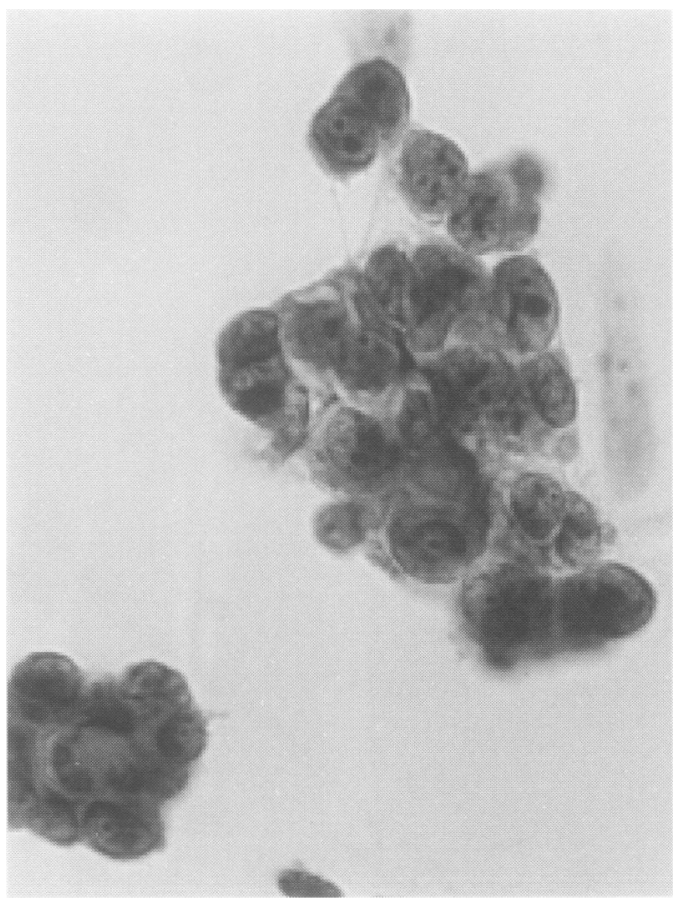

Figure 7 Clump of malignant cells in lumbar CSF from a patient with a primary tumour in the lung (haematoxylin and eosin).

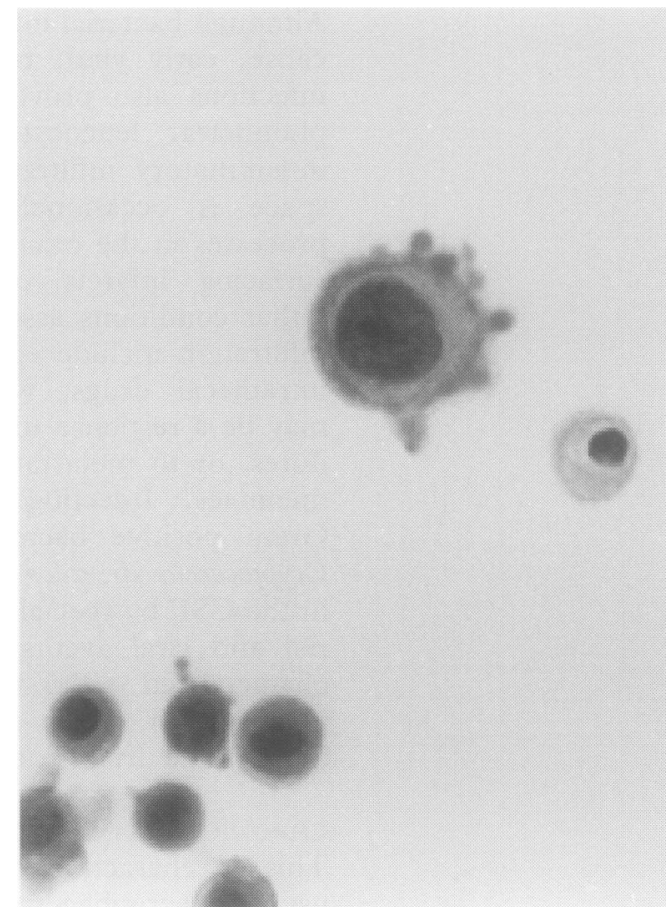

Figure 6 Carcinoma cells in lumbar CSF from a patient with a primary tumour in the breast (haematoxylin and eosin).

types. First, the presence of atypical cells (fig 10), which are abnormal but not clearly malignant, is always worrisome, and their interpretation should be undertaken with caution. The diagnostic problem arises when cells such as this are seen in very small numbers. Their presence should prompt a request for a repeat specimen. ${ }^{9}$ The problem is particularly acute when there is no history to suggest that the patient has a tumour. The presence of clumps of cells, or of mitotic

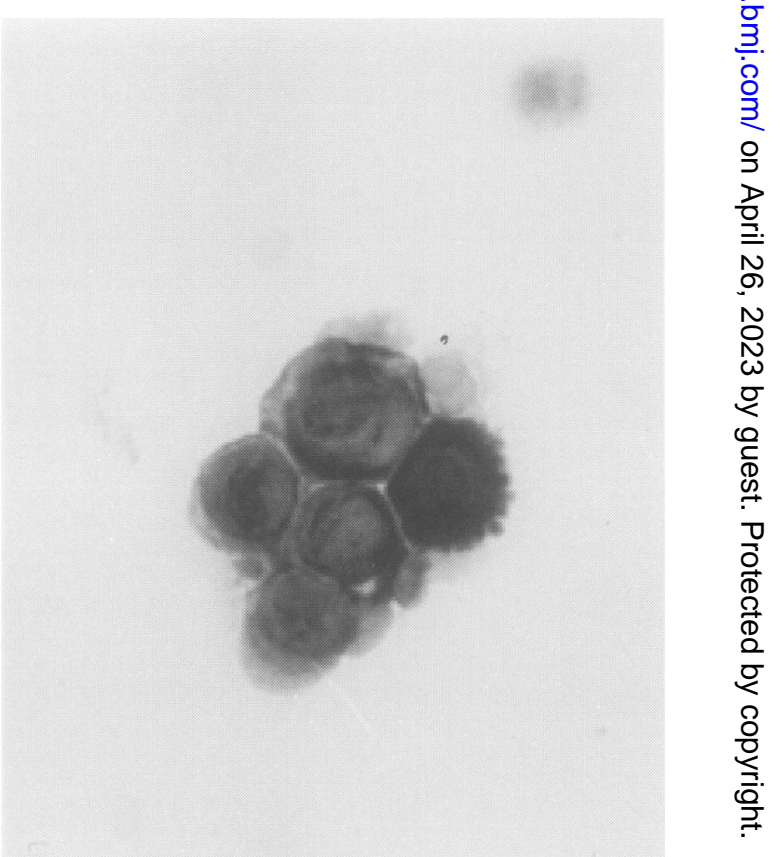

Figure 8 Malignant cells in CSF are positive for cytokeratin confirming their epithelial nature. Small nonmalignant cells in the sample are negative for cytokeratin (top right) (immunocytochemistry). 

malignant cells in CSF are positive for vimentin (negative cells are also seen in this preparation) in a patient with a paraspinal Ewing's sarcoma (immunocytochemistry).
Figure 9 Small

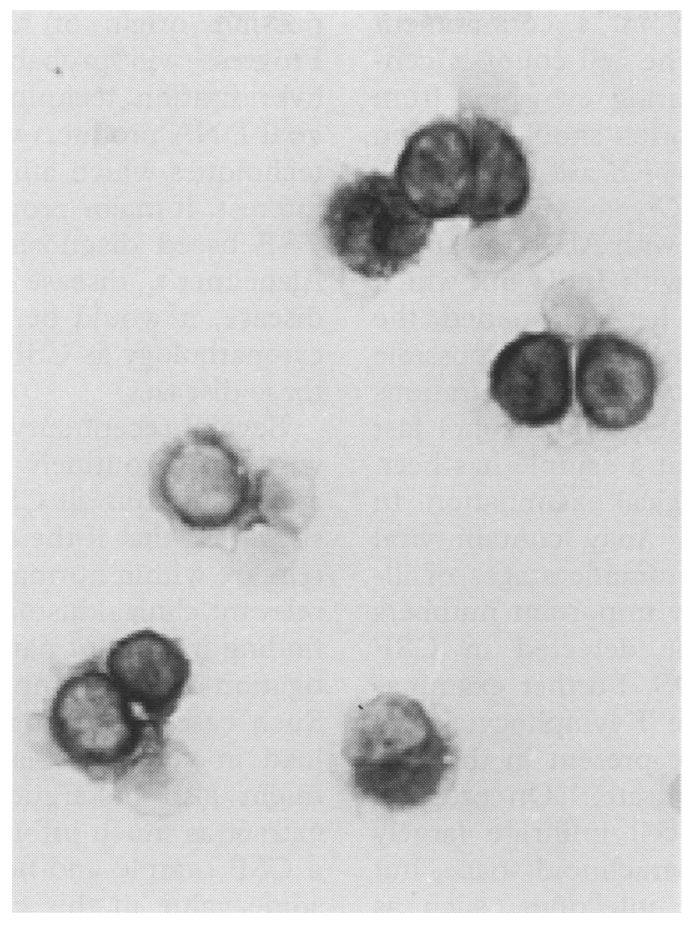

figures, should not be taken as indisputable evidence of malignancy, as both occur in non-neoplastic conditions. Clumps of cells may be found in cellular samples aspirated from ventricular cavities and occasionally in lumbar CSF. ${ }^{4}$ The cytological architecture is helpful in this context as the morphology of small choroid plexus fragments (fig 1), or even of cartilaginous fragments, is usually sufficiently characteristic to exclude the suspicion of malignancy. Mitotic figures are seen occasionally in reactive inflammatory infiltrates, particularly in macrophage-like cells. Cells may assume quite bizarre appearances in florid reactive processes and these may be sufficient to raise the suspicion of malig-

Figure 10 Several mononuclear cells are seen in this CSF. cytospin preparation from a 45 year old woman with relapsing/remitting brain stem disturbance, thought to be due to demyelination. Proteinaceous debris surrounds scattered cells, the largest of which has an irregular nucleus with variable chromatin density. The appearances are suspicious but not diagnostic of malignancy, (haematoxylin and eosin). nancy. Atypical cells may be present in such small numbers as to give uninformative spare cytospin preparations, in which case immunocytochemical studies will be unhelpful. Lumbar puncture may have to be repeated and the timing of this is likely to be influenced by the clinical progress of the patient.

A second major dilemma lies in the difficulty of distinguishing between reactive and neoplastic lymphocytic infiltrates. ${ }^{49}$ Cytological appearances of the cells may be helpful-monomorphic and lymphoblastic infiltrates suggest neoplasia whereas reactive infiltrates are usually of mixed cellularity. The presence of plasma cells is also helpful in pointing to a reactive rather than a neoplastic infiltrate as plasmacytoid lymphomas are very rare in the CNS. ${ }^{9}$ Immunocytochemical studies show that reactive infiltrates are composed of mixed T and B cells. Primary CNS lymphomas should show monoclonality, most being of B cell type. ${ }^{9}$ Difficulties arise because primary B cell lymphomas are frequently accompanied by a $T$ cell reaction: interpretation of immunocytochemical findings should be undertaken only with full knowledge of the clinical and radiological findings. If samples are inadequate for full immunocytochemical studies, a repeat sample must be requested.

Preventable pitfalls in CSF cytopathological diagnosis include inadequate clinical details and delay in transport to the laboratory, causing deterioration in cellular preservation, which specifically interferes with immunocytochemical staining properties. $^{9}$ Artefacts of preparation, such as cellular disruption, may be caused by excessive cytospin speeds. Discrepancies in appearance between different cytospin preparations from an individual sample may result from insufficient mixing of the original fluid or from unbalanced cytospin wells.

The differences between CSF samples from different sites have already been mentioned. If a ventriculoperitoneal shunt is in situ fluid obtained from the lower end of the shunt may be extremely cellular, containing clumps of bizarre-looking cells, probably of peritoneal origin, in which mitoses are not unusual. Paediatric CSF samples, especially from premature babies with intraventricular haemorrhage sometimes contain clusters of germinal matrix cells whose primitive appearance is suggestive of neoplasia to the inexperienced observer.

\section{Examination of high risk samples}

Certain categories of CSF samples may represent a particular hazard to laboratory staff. Most of these are infections in Advisory Committee on Dangerous Pathogens category 3, but Creutzfeldt-Jakob disease (category 2) is also a particular case. ${ }^{12}$ Samples taken from patients with known or suspected HIV infection, tuberculosis, or hepatitis $B$, and from possible cases of Creutzfeldt-Jakob disease should be treated as "high risk".

High risk samples of CSF should be trans- 
ported to, and handled in, a containment level three laboratory. The cell count is generally omitted. In preparing cytospins from such a sample, consideration should be given to the infective agents which are likely to be present. For instance, if Cryptococcus infection is suspected in a patient with AIDS, a sample of CSF may be mixed with India ink which will clearly outline, and leave unstained, the small spores of Cryptococcus. In possible tuberculous meningitis cytospin preparations should be analysed for acid and alcohol fast bacilli ${ }^{4}$ after ensuring that a sample has been submitted for bacteriological examination. In HIV infection the CSF may contain viral antigen in the pre-symptomatic stages of illness. Small but clinically important numbers of lymphocytes may be detected in CSF before the onset of AIDS. Further examination shows that these are $T$ lymphocytes and that very few $B$ cells are present in the preAIDS subarachnoid infiltrate. ${ }^{13}$ On progression to AIDS, the $T$ cell infiltrate largely disappears from the subarachnoid space, but additional opportunistic infections, such as Cryptococcus sp, may be accompanied by a polymorph response. An additional finding in AIDS may be the presence of primary B cell lymphoma infiltrate. It is the presence of HIV itself in CSF, rather than that of opportunistic agents, which represents a hazard to laboratory staff. Of the full range of possible infections in immunocompromised patients (not just AIDS cases) few, apart from Cryptococcus, are readily identifiable in cytological examination of CSF. ${ }^{9}$

As CSF shows no apparent abnormalities in Creutzfeldt-Jakob disease it is questionable whether lumbar puncture has any value in likely cases. CSF from patients with suspected Creutzfeldt-Jakob disease should be handled in a category 3 containment laboratory using disposable equipment where possible. All instruments and disposable items used in the lumbar puncture procedure should be destroyed by incineration. Laboratory equipment can be decontaminated by immersion in solutions containing 20000 ppm chlorine (14 Presept tablets freshly dissolved in $1000 \mathrm{ml}$ of water), or $2 \mathrm{~N}$ sodium hydroxide solution, or by steam autoclaving at $134^{\circ} \mathrm{C}$ for 18 minutes (porous load autoclave). It is preferable to dispose of equipment that has been contaminated with Creutzfeldt-Jakob disease agent. There is as yet no validated clinical test which would confirm or exclude the presence of Creutzfeldt-Jakob disease in life.

\section{Future trends in CSF diagnosis}

The number of problem cases in which it is hard to achieve a firm diagnosis following examination of CSF suggests that there is still room for progress in diagnostic procedures. ${ }^{14}$ Immunocytochemical techniques have helped to refine diagnosis and to separate specific cellular subpopulations in CSF. This helps to distinguish intrinsic from metastatic tumours in the subarachnoid space and to pinpoint the possible origin of metastatic tumour cells. Progress will probably be made in in situ hybridisation techniques identifying host or viral DNA products within cells, and in PCR techniques which amplify DNA fragments of interest. If major progress were to be made in CSF based diagnosis of conditions such as Alzheimer's disease and Creutzfeldt-Jakob disease, it would be unlikely to be based in cytopathology as CSF is generally acellular in these diseases.

Several recent surveys have questioned the wisdom of routinely analysing cytopathology appearances in all CSF samples. It has been suggested that if the cell count and CSF protein are within normal limits and if there is no relevant clinical history, then the likelihood of finding important pathology by further investigation of CSF samples is very low indeed. ${ }^{315}$ Such case selection might reduce the workload in very busy laboratories. However, it might also be argued that it is proper to extract as much information as possible from a CSF sample and negative results may have some value in this context. It is difficult to ascertain the number of cases in which major pathology is missed when CSF is reported as normal but several studies have shown that the number of false negative results is likely to be low. ${ }^{415}$ These matters are open to debate and may be influenced by local practice, especially at a time when cost effectiveness of hospital procedures is under close scrutiny. ${ }^{15}$

My thanks are due to $\mathrm{Mr}$ W Shade and the skilled technical staff of the Edinburgh Neuropathology Laboratory, to Dr J W Ironside for helpful discussion, and to Miss A Boyd for typing the manuscript.

1 Davson H, Welch K, Segal MB. The physiology and pathophysiology of the cerebrospinal fluid. Edinburgh: Churchill Livingstone, 1987.

2 Bell JE, Fryer AA, Collins M, et al. Developmental profile of plasma proteins in human fetal cerebrospinal fluid and blood. Neuropathol Appl Neurobiol 1991;17:441-56.

3 Hayward RA, Shapiro MF, Oye RK. Laboratory testing of cerebrospinal fluid. Lancet 1987;i:1-4.

4 Bigner SH. Cerebrospinal fluid (CSF) cytology: current status and diagnostic applications. F Neuropathol Exp Neurol 1992;51:235-45.

5 Rogers LR, Duchesneau PM, Nunez C. Comparison of cisternal and lumbar CSF examination in leptomeningeal metastases. Neurology 1992;42:1239-41.

6 Platt MS, McLure S, Clarke R, et al. Postmortem CSF pleocytosis. Am $\mathcal{F}$ Forens Med Pathol 1989;10:209-12.

7 Norenberg MD, Bruce-Gregorios J. Nervous system manifestations of systemic disease. In: Davis RL, Robertson DM, eds. Textbook of neuropathology. Second Edn. Baltimore: Williams and Wilkins, 1991:461-534.

8 Bigner SH, Johnston WW. Cytopathology of the central nervous system. New York: Masson Publishing, 1983.

nervous system. New York: Masson Publishing, 1983.
Walts AE. Cerebrospinal fluid cytology. Diagn Cytopathol 1992;8:394-408.

10 Seyfert S, Kabbeck-Kupijai D, Marx P, Kossmehl G. Cerebrospinal fluid cell preparation methods: an evaluation. Acta Cytol 1992;36:927-31.

11 Russell DS, Rubinstein LJ. Pathology of tumours of the nervous system. London: Edward Arnold, 1989.

12 Advisory Committee on Dangerous Pathogens. Categorisation of pathogens according to hazard and categories of containment. Second Edn. London: HMSO:1990.

13 Bell JE, Busutill A, Ironside JW, et al. Human immunodeficiency virus and the brain: Investigation of virus load and neuropathologic changes in pre-AIDS subjects. f Infect Dis 1993;168:818-24.

14 Andrews JM, Schumann GB. Laboratory processing of cerebrospinal fluid specimens. Diagn Cytopathol 1990; 6:139-43.

15 Fairbanks VF, Folger WN. Cost containment, quality assurance, and physician microscopy of cerebrospinal fluid with normal cell counts. Am f Clin Pathol 1990; 94:67-72. 